\title{
Original Research \\ Association of B-type natriuretic peptide with rapid progression in patients with aortic stenosis
}

\author{
Kangning Han ${ }^{1,2,3}$, Dongmei Shi ${ }^{1,2,3}$, Lixia Yang ${ }^{1,2,3}$, Meng Xie ${ }^{2,4}$, Zhijian Wang ${ }^{1,2,3}$, \\ Fei Gao ${ }^{1,2,3}$, Xiaoteng $\mathrm{Ma}^{1,2,3 *}$, Yujie Zhou ${ }^{1,2,3 *}$ \\ ${ }^{1}$ Department of Cardiology, Beijing Anzhen Hospital, Capital Medical University, 100029 Beijing, China \\ ${ }^{2}$ Beijing Institute of Heart, Lung and Blood Vessel Diseases, 100029 Beijing, China \\ ${ }^{3}$ The Key Laboratory of Remodeling-related Cardiovascular Disease, Ministry of Education, 100029 Beijing, China \\ ${ }^{4}$ Department of Echocardiogram, Beijing Anzhen Hospital, Capital Medical University, 100029 Beijing, China \\ *Correspondence: maxiaotengai@163.com (Xiaoteng Ma); azzyj12@163.com (Yujie Zhou) \\ Academic Editor: Nicola Gaibazzi \\ Submitted: 27 November 2021 Revised: 28 December 2021 Accepted: 4 January 2022 Published: 22 February 2022
}

\begin{abstract}
Background: Rapid progression of aortic stenosis (AS) is associated with poor outcomes, and the impact of B-type natriuretic peptide (BNP) on AS progression remains unknown. Objectives: The purpose of the present study was to investigate the association between BNP level and the AS progression rate. Methods: From January 2016 to June 2021, 200 AS patients with progression who had at least two transthoracic echocardiograms with a maximum interval of 180 days were retrospectively analyzed. Rapid progression of AS was defined as the annual increase of aortic jet velocity $(\operatorname{Vmax}) \geq 0.3 \mathrm{~m} / \mathrm{s} /$ year. For analyses, both the log-transformed BNP and the BNP ratio were used. The linear regression and binary logistic regression analyses were used to determine the association between BNP and the AS progression. Results: At a median echocardiographic follow-up of 595 days, the annual median (interquartile) progression of Vmax was $0.26(0.09-0.58) \mathrm{m} / \mathrm{s} /$ year. Patients with rapid progression had higher age, log BNP, and higher percentage of diabetes and male gender. Higher tertiles of $\log$ BNP and BNP ratio had more rapid increase in Vmax ( $p=0.018$ and 0.033 , respectively). BNP ratio significantly correlated with Vmax progression in univariate and multivariate linear regression analyses $(p<0.001$ and $p=0.001$, respectively). Moreover, both the univariate and multivariate binary logistic regression analyses showed that the log BNP and BNP ratio were associated with the rapid progression of AS ( $p<0.050$ for all). Conclusions: Higher BNP was independently associated with the rapid progression of AS.
\end{abstract}

Keywords: B-type natriuretic peptide; Aortic stenosis; Rapid progression; Transthoracic echocardiogram; Valvular disease

\section{Introduction}

Aortic stenosis (AS) is one of the most common valvular heart diseases, and its prevalence is rapidly increasing [1]. AS is a progressive disease, and the rapid progression of AS is associated with poor prognosis [2]. Currently, there is no available pharmacological therapy and aortic valve replacement (AVR) represents the only therapeutic strategy. AS progresses more rapidly in patients who require valve replacement in the future [3-5]. Studies showed the rapid progression of AS was one of the independent predictors for AVR, and those with rapid progression should undergo early AVR rather than when symptoms occur $[2,6]$. An early AVR on asymptomatic severe patients was associated with a more significant reduction in mortality [7]. Echocardiogram plays a key role in AS, where the different echocardiographic parameters were used for AS diagnosis and prognostic stratification [8]. Many studies graded rapid progression according to the cutoff value of an annual increase of aortic jet velocity $(\mathrm{Vmax}) \geq 0.3 \mathrm{~m} / \mathrm{s} /$ year [2,9]. Clinically, both the American College of Cardiology (ACC) and European Society of Cardiology (ESC) guidelines consider an annual Vmax increase $\geq 0.3 \mathrm{~m} / \mathrm{s} /$ year as one of the indications for AVR (classes of recommendations: IIa, level of evidence: B-C) [4,10,11]. Identification of clinical predictors for rapid progression may allow for the secondary prevention.

Ventricular cardiomyocytes predominantly secrete Btype natriuretic peptide (BNP) in response to increased wall stress before the symptoms appear. Previous studies found that increased BNP level was related to poor prognosis in AS patients. Patients with higher BNP had more adverse events and more severe status [12-14]. However, little is known about the relationship between BNP and the progression rate of AS. Thus, the objective of our study was to assess the relationship between the baseline BNP and the AS progression rate.

\section{Methods}

\subsection{Study population}

AS patients were consecutively identified by the electronic medical system of Beijing Anzhen Hospital, Capital Medical University (Beijing, China) from January 2016 to June 2021. Transthoracic echocardiogram was used to diagnose the AS according to the Vmax and mean pres- 
sure gradient (MPG): (1) mild AS (Vmax 2.00-2.99 m/s and/or MPG 10.0-19.9 mmHg); (2) moderate AS (Vmax $3.00-3.99 \mathrm{~m} / \mathrm{s}$ and/or MPG 20.0-39.9 mmHg); (3) severe AS (Vmax $\geq 4.00 \mathrm{~m} / \mathrm{s}$ and $/$ or MPG $\geq 40.0 \mathrm{mmHg}$ ) [15]. Patients were enrolled in the present study if they had at least two transthoracic echocardiograms with a maximal interval $\geq 180$ days. Patients were excluded if they had any of the following conditions: (1) congenital heart diseases other than bicuspid aortic valve (BAV); (2) history of surgical or transcatheter aortic valve replacement (TAVR); (3) lack of clinical or laboratory data; (4) left ventricular ejection fraction (LVEF) $<40 \%$. If the patient underwent multiple echocardiograms with maximal intervals $\geq 180$ days, the one with the highest Vmax was chosen as the last echocardiogram. Annual Vmax progression was calculated based on the first and last echocardiograms. Rapid progression of Vmax was defined as the annual increase $\geq 0.3 \mathrm{~m} / \mathrm{s} /$ year.

\subsection{Statistical analyses}

Continuous and categorical variables were expressed as mean $\pm \mathrm{SD}$, median with interquartile range, or number with percentage when appropriate. Because BNP was not normally distributed, log transformation of BNP was used for continuous variable analysis. BNP ratio was the measured BNP divided by the maximum normal range for a specific sex and age. Patients were stratified into three groups according to the tertiles of $\log$ BNP and BNP ratio, respectively. For groupwise comparisons of continuous variables, $t$ test, Mann-Whitney U test, and Kruskal-Wallis test were used appropriately. Both the univariate and multivariate analyses of linear regression and binary logistic regression were used to evaluate the association between BNP and Vmax progression. To avoid co-linearity among AS severity variables, we entered only Vmax in the multivariate model. Statistical analyses were conducted by SPSS 26.0 (IBM Corp, Armonk, NY, USA) where $p<0.05$ was considered significant.

\section{Results}

The baseline clinical, laboratory, and echocardiographic characteristics of the population $(n=200)$ are presented in Table 1. The mean age was $66 \pm 11$ years, $52 \%$ were female, and the baseline Vmax was $3.47 \pm 0.73 \mathrm{~m} / \mathrm{s}$. Patients with rapid progression were older, more likely to be male, had higher log BNP, and a higher percentage of diabetes. As shown in Table 2, as the log BNP tertiles increased from $\mathrm{T} 1$ to $\mathrm{T} 3$, patients became older, had a higher percentage of heart failure, lower LVEF, higher baseline Vmax, baseline MPG, more rapid progression of Vmax, and a lower percentage of BAV, dyslipidemia and statins intake.

During the median follow-up of 595 days, the overall median (interquartile) progression of Vmax was 0.26 $(0.09-0.58) \mathrm{m} / \mathrm{s} /$ year and of MPG was 4.68 (1.22-9.36) $\mathrm{mmHg}$ /year. Patients in higher tertiles of log BNP had more rapid Vmax progression $(p=0.018)$ (Fig. 1). Similarly, considering the tertiles of the BNP ratio, patients in high tertiles progressed more rapidly ( $p=0.033$ ) (Fig. 1).

In univariate linear regression analysis, $\log \mathrm{BNP}$ was positively associated with Vmax progression $(\beta=0.157, p$ $=0.009$ ). However, this correlation was not significant in multivariate linear regression analysis $(p=0.062)$ (Table 3 ). BNP ratio was positively correlated with Vmax progression in univariate $(\beta=0.014, p<0.001)$ and multivariate $(\beta$ $=0.012, p=0.001)$ linear regression analyses (Table 4). In univariate binary logistic analysis, $\log$ BNP was associated with rapid progression of $\mathrm{Vmax}(\mathrm{OR}=1.839 ; 95 \%$ CI: $1.028-3.292, p=0.040$ ). After adjusting the covariates, this association was still significant $(\mathrm{OR}=2.424 ; 95 \% \mathrm{CI}$ : 1.108-5.307, $p=0.027$ ) (Table 5). We further used BNP ratio to detect the association between BNP and rapid progression. We found higher BNP ratio was associated with rapid progression $(\mathrm{OR}=1.112 ; 95 \% \mathrm{CI}: 1.022-1.209, p=$ $0.013)$. In multivariate analysis, BNP ratio was the independent predictor for rapid progression $(\mathrm{OR}=1.134 ; 95 \% \mathrm{CI}$ : $1.020-1.261, p=0.020$ ) (Table 6). Further subgroup analysis was performed according to BAV. BNP ratio was significantly associated with rapid progression of AS in BAV patients (OR $=1.329,95 \%$ CI: $1.021-1.731, p=0.034)$. However, after excluding BAV, this association was not significant $(\mathrm{OR}=1.074,95 \%$ CI: $0.989-1.166, p=0.092)$. There was no significant interaction between the presence and absence of BAV ( $p$ for interaction $=0.130$ ).

\section{Discussion}

The present study showed the quantitative association between BNP at first echocardiogram and AS progression, emphasizing the significance of BNP in predicting AS progression. Higher BNP was the independent predictor for the rapid progression of AS.

BNP is a hormone released from the myocardium under increased wall stress in the setting of volume expansion and pressure overload. BNP is a globally acceptable biomarker for heart failure and is elevated in patients with AS. Using BNP could be viewed as a surrogate marker of disease progression as it correlates with functional status, symptom onset, and disease severity in AS patients. BNP was associated with left ventricular (LV) diastolic function [16], LV end-systolic wall stress [17], and LV hypertrophy [18], suggesting that the higher BNP could cause symptoms and poor prognosis. AS was associated with cardiac remodeling in response to pressure overload, which was reflected by different geometric ventricular patterns. AS patients were more likely to have concentric hypertrophy. Symptomatic AS patients had significantly more percentage of mixed hypertrophy than asymptomatic patients, underlying the potential association between cardiac remodeling and prognosis [19]. A cross-sectional study showed symptomatic patients had significantly higher BNP [14]. Asymptomatic patients who developed symptoms during follow-up had higher BNP levels compared with those who 
Table 1. Baseline characteristics of the study population according to Vmax progression.

\begin{tabular}{|c|c|c|c|c|}
\hline Variables & All patients & Slow progression & Rapid progression & $p$ value \\
\hline Age (years) & $66 \pm 11$ & $64 \pm 12$ & $68 \pm 10$ & 0.005 \\
\hline Female, n $(\%)$ & $104(52.0)$ & $47(65.3)$ & $57(44.5)$ & 0.005 \\
\hline Smoking, n (\%) & $46(23.0)$ & $15(20.8)$ & $31(24.2)$ & 0.585 \\
\hline Hypertension, n (\%) & $146(73.0)$ & $52(72.2)$ & $94(73.4)$ & 0.853 \\
\hline Diabetes, n (\%) & $53(26.5)$ & $11(15.3)$ & $42(32.8)$ & 0.007 \\
\hline Dyslipidemia, n (\%) & $105(52.5)$ & $32(44.4)$ & $73(57.0)$ & 0.087 \\
\hline $\mathrm{CAD}, \mathrm{n}(\%)$ & $84(42.0)$ & $24(33.3)$ & $60(46.9)$ & 0.063 \\
\hline CKD, n (\%) & $19(9.5)$ & $8(11.1)$ & $11(8.6)$ & 0.560 \\
\hline Heart failure, n (\%) & $24(12.0)$ & $10(13.9)$ & $14(10.9)$ & 0.538 \\
\hline Statins, n (\%) & $87(43.5)$ & $23(31.9)$ & $64(50.0)$ & 0.013 \\
\hline ACEI/ARBs, n (\%) & $68(34.0)$ & $22(30.6)$ & $46(35.9)$ & 0.441 \\
\hline Baseline LVEF (\%) & $65(60-68)$ & $65(60-68)$ & $63(58-68)$ & 0.338 \\
\hline $\mathrm{BNP}(\mathrm{pg} / \mathrm{mL})$ & $195(73-393)$ & $197(63-323)$ & $213(87-481)$ & 0.073 \\
\hline $\log \mathrm{BNP}$ & $2.23 \pm 0.48$ & $2.18 \pm 0.47$ & $2.34 \pm 0.53$ & 0.039 \\
\hline BNP ratio & $2.04(0.97-4.63)$ & $2.1(0.8-3.8)$ & $2.4(1.1-6.7)$ & 0.052 \\
\hline Creatinine $(\mu \mathrm{mol} / \mathrm{L})$ & $72.7(60.4-89.2)$ & $72.9(57.5-93.1)$ & $72.2(61.7-85.1)$ & 0.784 \\
\hline Baseline $\operatorname{Vmax}(\mathrm{m} / \mathrm{s})$ & $3.47 \pm 0.73$ & $3.50 \pm 0.78$ & $3.45 \pm 0.70$ & 0.617 \\
\hline Baseline MPG (mmHg) & $30 \pm 1$ & $29 \pm 13$ & $29 \pm 13$ & 0.987 \\
\hline Vmax progression $(\mathrm{m} / \mathrm{s} /$ year $)$ & $0.26(0.09-0.58)$ & $0.04(0.01-0.11)$ & $0.46(0.26-0.72)$ & $<0.001$ \\
\hline $\mathrm{BAV}, \mathrm{n}(\%)$ & $54(27.0)$ & $22(30.6)$ & $32(25.0)$ & 0.396 \\
\hline
\end{tabular}

$\mathrm{CAD}$, coronary artery disease; CKD, chronic kidney disease; ACEI/ARBs, angiotensin converting enzyme inhibitor/angiotensin receptor blockers; LVEF, left ventricular ejection fraction; BNP, B-type natriuretic peptide; Vmax, aortic jet velocity; MPG, mean pressure gradient; BAV, bicuspid aortic valve.

Table 2. Baseline characteristics of the study population according to $\log$ BNP tertiles.

\begin{tabular}{|c|c|c|c|c|}
\hline Variables & $\mathrm{T} 1$ & $\mathrm{~T} 2$ & $\mathrm{~T} 3$ & $p$ value \\
\hline Age (years) & $63 \pm 10$ & $67 \pm 10$ & $69 \pm 12$ & 0.005 \\
\hline Female, n (\%) & $32(48.5)$ & $42(62.7)$ & $30(45.5)$ & 0.104 \\
\hline Smoking, n (\%) & $11(16.7)$ & $15(22.4)$ & $19(28.8)$ & 0.250 \\
\hline Hypertension, $\mathrm{n}(\%)$ & $47(71.2)$ & $53(79.1)$ & $45(68.2)$ & 0.343 \\
\hline Diabetes, n (\%) & $19(28.8)$ & $17(25.4)$ & $16(24.2)$ & 0.826 \\
\hline Dyslipidemia, n (\%) & $42(63.6)$ & $36(53.7)$ & $26(39.4)$ & 0.020 \\
\hline CAD, n (\%) & $32(48.5)$ & $26(38.8)$ & $25(37.9)$ & 0.391 \\
\hline CKD, n (\%) & $4(6.1)$ & $6(9.0)$ & $9(13.6)$ & 0.327 \\
\hline Heart failure, n (\%) & $1(1.5)$ & $11(16.4)$ & $11(16.7)$ & 0.008 \\
\hline Statins, n (\%) & $38(57.6)$ & $30(44.8)$ & $19(28.8)$ & 0.004 \\
\hline ACEI/ARBs, n (\%) & $28(42.4)$ & $22(32.8)$ & $18(27.3)$ & 0.178 \\
\hline Baseline LVEF (\%) & $65(62-68)$ & $64(57-68)$ & $62(58-65)$ & 0.006 \\
\hline $\mathrm{BNP}$ ratio & $0.63(0.46-0.99)$ & $2.32(1.71-3.20)$ & $7.65(5.39-12.16)$ & $<0.001$ \\
\hline Creatinine $(\mu \mathrm{mol} / \mathrm{L})$ & $69.9(58.1-79.4)$ & $66.7(58.5-79.9)$ & $82.1(68.2-105.9)$ & $<0.001$ \\
\hline Baseline Vmax (m/s) & $3.28 \pm 0.66$ & $3.44 \pm 0.69$ & $3.68 \pm 0.78$ & 0.006 \\
\hline Baseline MPG (mmHg) & $25 \pm 11$ & $28 \pm 12$ & $33 \pm 15$ & 0.001 \\
\hline Vmax progression (m/s/year) & $0.19(0.03-0.45)$ & $0.31(0.10-0.61)$ & $0.34(0.12-0.66)$ & 0.019 \\
\hline $\mathrm{BAV}, \mathrm{n}(\%)$ & $29(43.9)$ & $13(19.4)$ & $12(18.2)$ & 0.001 \\
\hline
\end{tabular}

Abbreviations as in Table 1. 

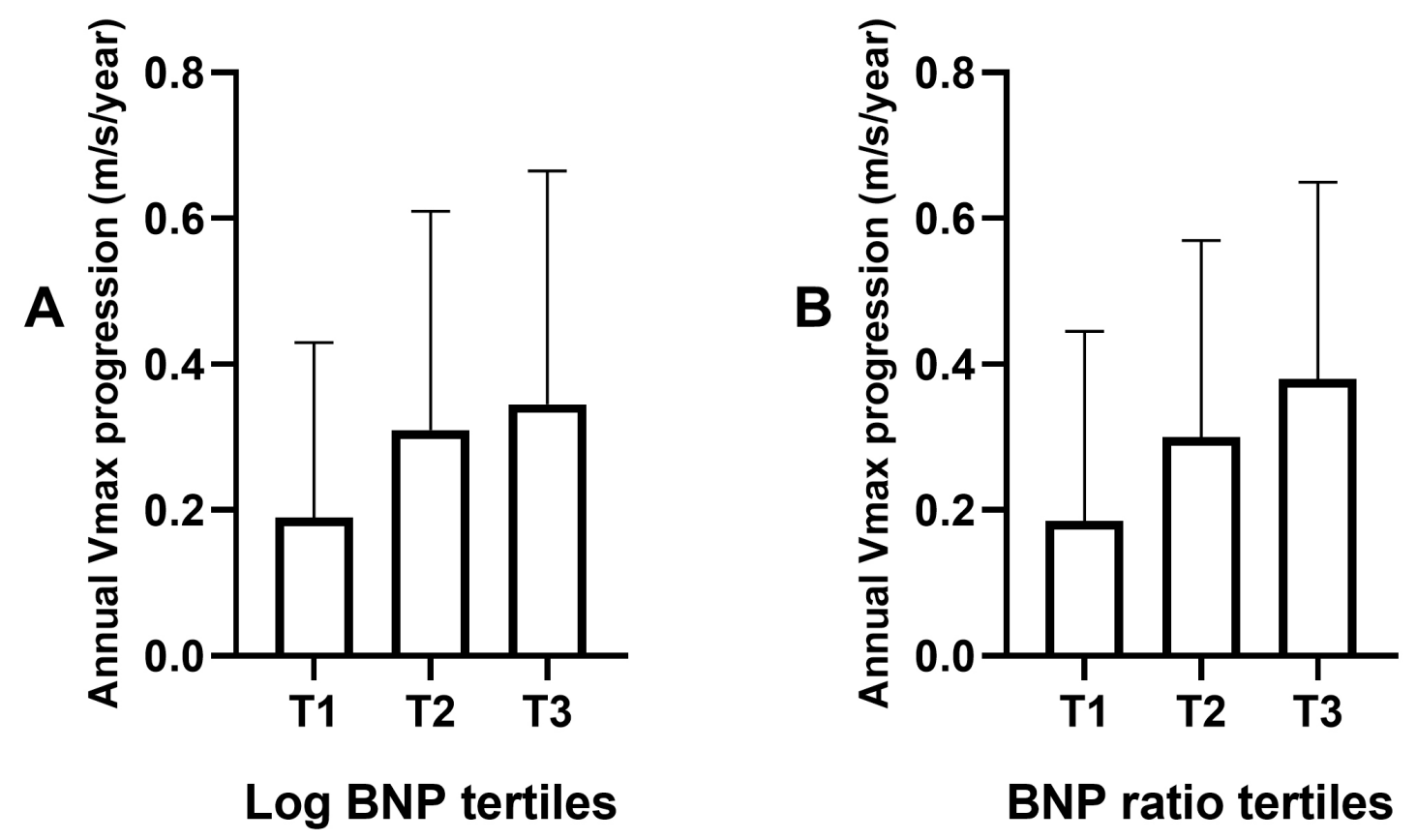

Fig. 1. Comparison of annual Vmax progression across different tertiles BNP. (A) Log BNP. (B) BNP ratio. Vmax progression is expressed as median \pm interquartile range.

Table 3. Univariate and multivariate linear regression analyses between log BNP and Vmax progression.

\begin{tabular}{lcccccc}
\hline \multirow{2}{*}{ Variable } & \multicolumn{3}{c}{ Univariate } & \multicolumn{3}{c}{ Multivariate } \\
\cline { 2 - 7 } & $\beta$ & Standard $\beta$ & $p$ value & $\beta$ & Standard $\beta$ & $p$ value \\
\hline Log BNP & 0.157 & 0.184 & 0.009 & 0.134 & 0.157 & 0.062 \\
Age & 0.005 & 0.121 & 0.089 & 0.002 & 0.053 & 0.691 \\
Female & -0.218 & -0.248 & $<0.001$ & -0.222 & -0.252 & 0.003 \\
Smoking & 0.098 & 0.094 & 0.187 & -0.057 & -0.054 & 0.497 \\
Hypertension & -0.062 & -0.063 & 0.377 & -0.096 & -0.097 & 0.200 \\
Diabetes & 0.076 & 0.077 & 0.282 & 0.064 & 0.064 & 0.382 \\
Dyslipidemia & -0.012 & -0.014 & 0.847 & -0.027 & -0.030 & 0.712 \\
CAD & 0.057 & 0.064 & 0.372 & -0.003 & -0.003 & 0.966 \\
Heart failure & -0.062 & -0.046 & 0.521 & -0.110 & -0.081 & 0.279 \\
Creatinine & 0.001 & 0.086 & 0.226 & 0.001 & 0.057 & 0.438 \\
BAV & -0.064 & -0.064 & 0.365 & -0.023 & -0.023 & 0.755 \\
LVEF & -0.013 & -0.198 & 0.005 & -0.009 & -0.130 & 0.080 \\
Baseline Vmax & -0.005 & -0.008 & 0.905 & -0.047 & -0.078 & 0.304 \\
\hline BNP, B-type & & &
\end{tabular}

$\mathrm{BNP}$, B-type natriuretic peptide; CAD, coronary artery disease; BAV, bicuspid aortic valve; LVEF, left ventricular ejection fraction; Vmax, aortic jet velocity.

remained asymptomatic [20]. Higher annualized BNP progression could be a sign of the progressive exhaustion of LV adaption to the increased afterload, which precedes the occurrence of symptoms [21]. Previous study has shown that BNP level is positively correlated with Vmax and MPG, and negatively correlated with aortic valve area [14]. The progression of AS could affect the cardiac remodeling (e.g., hypertrophy), which could secondarily enhance the secretion of BNP. Therefore, higher BNP may be an indication of AS progression.
BNP could predict the prognosis of AS patients [20]. A higher BNP was associated with an increased risk of adverse outcomes in asymptomatic severe AS patients with normal LVEF who were not referred for AVR [13]. Moreover, a higher annualized BNP increase in asymptomatic patients without AVR was related to a higher rate of adverse cardiac events [21]. The relationship between preprocedural high BNP levels and worse outcomes after AVR has been demonstrated in several studies [12,20]. Higher BNP before TAVR was associated with an increased risk 
Table 4. Univariate and multivariate linear regression analyses between BNP ratio and Vmax progression.

\begin{tabular}{lcccccc}
\hline \multirow{2}{*}{ Variable } & \multicolumn{3}{c}{ Univariate } & \multicolumn{3}{c}{ Multivariate } \\
\cline { 2 - 7 } & $\beta$ & Standard $\beta$ & $p$ value & $\beta$ & Standard $\beta$ & $p$ value \\
\hline BNP ratio & 0.014 & 0.286 & $<0.001$ & 0.012 & 0.239 & 0.001 \\
Age & 0.005 & 0.121 & 0.089 & 0.004 & 0.111 & 0.139 \\
Female & -0.218 & -0.248 & $<0.001$ & -0.175 & -0.198 & 0.018 \\
Smoking & 0.098 & 0.094 & 0.187 & -0.036 & -0.034 & 0.658 \\
Hypertension & -0.062 & -0.063 & 0.377 & -0.104 & -0.105 & 0.156 \\
Diabetes & 0.076 & 0.077 & 0.282 & 0.056 & 0.056 & 0.436 \\
Dyslipidemia & -0.012 & -0.014 & 0.847 & -0.016 & -0.018 & 0.819 \\
CAD & 0.057 & 0.064 & 0.372 & -0.010 & -0.011 & 0.890 \\
Heart failure & -0.062 & -0.046 & 0.521 & -0.123 & -0.091 & 0.215 \\
Creatinine & 0.001 & 0.086 & 0.226 & 0.001 & 0.045 & 0.538 \\
BAV & -0.064 & -0.064 & 0.365 & -0.022 & -0.023 & 0.751 \\
LVEF & -0.013 & -0.198 & 0.005 & -0.008 & -0.119 & 0.099 \\
Baseline Vmax & -0.005 & -0.008 & 0.905 & -0.043 & -0.070 & 0.328 \\
\hline Abbreviations & in & & & & &
\end{tabular}

Abbreviations as in Table 3.

Table 5. Univariate and multivariate logistic regression analyses between log BNP and Vmax progression.

\begin{tabular}{|c|c|c|c|c|c|c|}
\hline \multirow{2}{*}{ Variables } & \multicolumn{3}{|c|}{ Univariate } & \multicolumn{3}{|c|}{ Multivariate } \\
\hline & OR & $95 \% \mathrm{CI}$ & $p$ value & OR & $95 \% \mathrm{CI}$ & $p$ value \\
\hline Log BNP & 1.839 & $1.028-3.292$ & 0.040 & 2.424 & $1.108-5.307$ & 0.027 \\
\hline Age & 1.039 & $1.011-1.068$ & 0.007 & 1.033 & $0.999-1.067$ & 0.055 \\
\hline Female & 0.427 & $0.235-0.776$ & 0.005 & 0.352 & $0.157-0.792$ & 0.012 \\
\hline Smoking & 1.214 & $0.604-2.440$ & 0.585 & 0.581 & $0.234-1.442$ & 0.242 \\
\hline Hypertension & 1.063 & $0.556-2.033$ & 0.853 & 0.624 & $0.286-1.359$ & 0.235 \\
\hline Diabetes & 2.708 & $1.292-5.679$ & 0.008 & 2.312 & $1.020-5.239$ & 0.045 \\
\hline Dyslipidemia & 1.659 & $0.927-2.969$ & 0.088 & 1.614 & $0.763-3.417$ & 0.211 \\
\hline CAD & 1.765 & $0.968-3.217$ & 0.064 & 0.990 & $0.467-2.096$ & 0.978 \\
\hline Heart failure & 0.761 & $0.319-1.815$ & 0.538 & 0.619 & $0.219-1.750$ & 0.365 \\
\hline Creatinine & 1.001 & $0.996-1.006$ & 0.711 & 0.999 & $0.995-1.004$ & 0.796 \\
\hline BAV & 0.758 & $0.399-1.439$ & 0.396 & 0.967 & $0.456-2.050$ & 0.931 \\
\hline LVEF & 0.972 & $0.929-1.017$ & 0.223 & 1.009 & $0.958-1.062$ & 0.742 \\
\hline Baseline Vmax & 0.900 & $0.605-1.339$ & 0.603 & 0.742 & $0.461-1.194$ & 0.219 \\
\hline
\end{tabular}

Abbreviations as in Table 3.

for adverse events [12,22]. Preoperative BNP could predict death after surgical aortic valve replacement, which is even more accurate than logistic EuroSCORE [20]. An elevated BNP level on arrival in intensive care unit is an independent predictor of postoperative heart failure after AVR [23]. Sato showed TAVR could gradually decrease the BNP in AS patients during follow-up, coinciding with cardiac structure and function recovery. A subsequent increase of BNP after TAVR was associated with higher mortality [24]. Aortic balloon valvuloplasty in severe AS patients could decrease the BNP level [25]. Additionally, BNP 24h post-procedure could predict the 1-year mortality after TAVR [26].

Besides the rapid progression of Vmax, higher BNP is one of the indications for AVR. Patients with higher BNP were more likely to undergo intervention during follow-up
[20]. According to the ESC guideline for valvular disease, marked BNP elevation in asymptomatic severe AS patients with normal LVEF was an indication for AVR [11]. In ACC guideline, AVR is reasonable when BNP $>3$ times normal in asymptomatic severe AS patients [10]. Our investigation supported the importance of BNP and rapid Vmax progression in AVR indications since both were linked with the poor outcome.

BNP level is higher in older people and women than in younger people and men [27]. In fact, using age- and sexspecific BNP levels can improve the diagnostic accuracy [28]. BNP ratio, the ratio of measured BNP to BNP reference values for a specific age and sex, can reflect the state of BNP activation and cardiac function. A higher BNP ratio was shown to be associated with higher mortality in AS 
Table 6. Univariate and multivariate logistic regression analyses between BNP ratio and Vmax progression.

\begin{tabular}{|c|c|c|c|c|c|c|}
\hline \multirow{2}{*}{ Variables } & \multicolumn{3}{|c|}{ Univariate } & \multicolumn{3}{|c|}{ Multivariate } \\
\hline & OR & $95 \% \mathrm{CI}$ & $p$ value & OR & $95 \% \mathrm{CI}$ & $p$ value \\
\hline BNP ratio & 1.112 & $1.022-1.209$ & 0.013 & 1.134 & $1.020-1.261$ & 0.020 \\
\hline Age & 1.039 & $1.011-1.068$ & 0.007 & 1.042 & $1.007-1.077$ & 0.016 \\
\hline Female & 0.427 & $0.235-0.776$ & 0.005 & 0.459 & $0.205-1.028$ & 0.059 \\
\hline Smoking & 1.214 & $0.604-2.440$ & 0.585 & 0.613 & $0.246-1.529$ & 0.294 \\
\hline Hypertension & 1.063 & $0.556-2.033$ & 0.853 & 0.635 & $0.289-1.399$ & 0.260 \\
\hline Diabetes & 2.708 & $1.292-5.679$ & 0.008 & 2.200 & $0.961-5.036$ & 0.062 \\
\hline Dyslipidemia & 1.659 & $0.927-2.969$ & 0.088 & 1.617 & $0.763-3.429$ & 0.210 \\
\hline CAD & 1.765 & $0.968-3.217$ & 0.064 & 0.996 & $0.466-2.126$ & 0.991 \\
\hline Heart failure & 0.761 & $0.319-1.815$ & 0.538 & 0.581 & $0.199-1.690$ & 0.319 \\
\hline Creatinine & 1.001 & $0.996-1.006$ & 0.711 & 0.999 & $0.994-1.004$ & 0.747 \\
\hline BAV & 0.758 & $0.399-1.439$ & 0.396 & 0.932 & $0.445-1.951$ & 0.852 \\
\hline LVEF & 0.972 & $0.929-1.017$ & 0.223 & 1.008 & $0.958-1.062$ & 0.750 \\
\hline Baseline Vmax & 0.900 & $0.605-1.339$ & 0.603 & 0.761 & $0.476-1.218$ & 0.255 \\
\hline
\end{tabular}

Abbreviations as in Table 3.

[29]. Consistent with the log BNP, we showed BNP ratio was also associated with rapid progression of AS, strengthening its role in AS prediction.

\section{Limitation}

The data set was confined to the Chinese population, implying that ethnic distinctions cannot be eliminated. Second, we used baseline BNP levels and could not assess the effect of temporal variations on the link with AS progression. Third, the aortic valve area was not included in this study since it was not frequently assessed in our center. Fourth, chronic kidney disease (CKD) could affect the level of BNP [30], but in this study we adjusted creatinine (as indicator of CKD) in the multivariate analyses. Fifth, because of retrospective nature of our study which mainly included outpatients, we failed to obtain all patients' weight and height, and therefore body mass index could not be calculated. Sixth, we did not use cardiac remodeling parameters to further detect the association between BNP and AS.

\section{Conclusions}

In this study, we showed a significant and independent association between BNP and the rapid advancement of AS. Patients with higher BNP were more likely to have a rapid progression, which may have a prognostic role in clinical decision. Additional prospective studies are required to corroborate our findings.

\section{Author contributions}

Conceptualization-KH, $\mathrm{XM}$ and $\mathrm{YZ}$; methodology- $\mathrm{KH}, \quad \mathrm{MX}$ and $\mathrm{XM}$; software- $\mathrm{KH}$ and $\mathrm{XM}$; validation-DS and LY; formal analysis$\mathrm{KH}$; investigation- $\mathrm{KH}$; resources-XM and $\mathrm{YZ}$; data curation-XM and $\mathrm{YZ}$; writing-original draft preparation- $\mathrm{KH}$; writing - review and editing - ZW, FG, $\mathrm{XM}$ and $\mathrm{YZ}$; visualization-KH; supervision- $-\mathrm{YZ}$; project administration-YZ; funding acquisition-XM and $\mathrm{YZ}$. All authors have read and agreed to the published version of the manuscript.

\section{Ethics approval and consent to participate}

Not applicable.

\section{Acknowledgment}

Not applicable.

\section{Funding}

This work was supported by National Key Research and Development Program of China (2017YFC0908800), China Postdoctoral Science Foundation (2021M692253), Beijing Postdoctoral Research Foundation (2021-ZZ-023), and Beijing Municipal Administration of Hospitals Mission Plan (SML20180601).

\section{Conflict of interest}

The authors declare no conflict of interest.

\section{References}

[1] Iung B, Baron G, Butchart EG, Delahaye F, Gohlke-Bärwolf C, Levang OW, et al. A prospective survey of patients with valvular heart disease in Europe: the Euro Heart Survey on Valvular Heart Disease. European Heart Journal. 2003; 24: 1231-1243.

[2] Nistri S, Faggiano P, Olivotto I, Papesso B, Bordonali T, Vescovo G, et al. Hemodynamic Progression and Outcome of Asymptomatic Aortic Stenosis in Primary Care. The American Journal of Cardiology. 2012; 109: 718-723.

[3] Otto CM, Pearlman AS, Gardner CL. Hemodynamic progression of aortic stenosis in adults assessed by doppler echocardio- 
graphy. Journal of the American College of Cardiology. 1989; 13: $545-550$

[4] Roger VL, Tajik AJ, Bailey KR, Oh JK, Taylor CL, Seward JB. Progression of aortic stenosis in adults: Newappraisal using doppler echocardiography. American Heart Journal. 1990; 119: 331-338.

[5] Rosenhek R, Binder T, Porenta G, Lang I, Christ G, Schemper $\mathrm{M}$, et al. Predictors of Outcome in Severe, Asymptomatic Aortic Stenosis. New England Journal of Medicine. 2000; 343: 611617.

[6] van der Linde D, Andrinopoulou E, Oechslin EN, Budts W, van Dijk APJ, Pieper PG, et al. Congenital valvular aortic stenosis in young adults: Predictors for rate of progression of stenosis and aortic dilatation. International Journal of Cardiology. 2013; 168: 863-870.

[7] Gahl B, Çelik M, Head SJ, Vanoverschelde J, Pibarot P, Reardon MJ, et al. Natural History of Asymptomatic Severe Aortic Stenosis and the Association of Early Intervention with Outcomes. JAMA Cardiology. 2020; 5: 1102-1112.

[8] Antonini-Canterin F, Di Nora C, Cervesato E, Zito C, Carerj $\mathrm{S}$, Ravasel $\mathrm{A}$, et al. Value of ejection fraction/velocity ratio in the prognostic stratification of patients with asymptomatic aortic valve stenosis. Echocardiography. 2018; 35: 1909-1914.

[9] Mateos N, Gómez M, Homar A, Garcia-Elias A, Yáñez L, Tajes $\mathrm{M}$, et al. Plasmatic PCSK9 levels are associated with very fast progression of asymptomatic degenerative aortic stenosis. Journal of Cardiovascular Translational Research. 2021. (in press)

[10] Otto CM, Nishimura RA, Bonow RO, Carabello BA, Erwin JP 3rd, Gentile F, et al. 2020 ACC/AHA guideline for the management of patients with valvular heart disease: Executive summary a report of the American College of Cardiology/American Heart Association joint committee on clinical practice guidelines. Circulation. 2021; 143: e35-e71.

[11] Baumgartner H, Falk V, Bax JJ, De Bonis M, Hamm C, Holm PJ, et al. 2017 ESC/EACTS Guidelines for the management of valvular heart disease. European Heart Journal. 2017; 38: 27392791.

[12] O'Sullivan CJ, Stortecky S, Heg D, Jüni P, Windecker S, Wenaweser P. Impact of B-type natriuretic peptide on short-term clinical outcomes following transcatheter aortic valve implantation. EuroIntervention. 2015; 10: e1-e8.

[13] Nakatsuma K, Taniguchi T, Morimoto T, Shiomi H, Ando K, Kanamori N, et al. B-type natriuretic peptide in patients with asymptomatic severe aortic stenosis. Heart. 2019; 105: 384-390.

[14] Gerber IL, Stewart RAH, Legget ME, West TM, French RL, Sutton TM, et al. Increased Plasma Natriuretic Peptide Levels Reflect Symptom Onset in Aortic Stenosis. Circulation. 2003; 107: 1884-1890.

[15] Yang L, Boler A, Medina-Inojosa JR, Scott CG, Maurer MJ, Eleid MF, et al. Aortic Stenosis Progression, Cardiac Damage, and Survival. JACC: cardiovascular Imaging. 2021; 14: 11131126.

[16] Mannacio V, Antignano A, De Amicis V, Di Tommaso L, Giordano R, Iannelli G, et al. B-type natriuretic peptide as a biochemical marker of left ventricular diastolic function: assessment in asymptomatic patients 1 year after valve replacement for aortic stenosis. Interactive CardioVascular and Thoracic Surgery.
2013; 17: 371-377.

[17] Ikeda T, Matsuda K, Itoh H, Shirakami G, Miyamoto Y, Yoshimasa $\mathrm{T}$, et al. Plasma levels of brain and atrial natriuretic peptides elevate in proportion to left ventricular end-systolic wall stress in patients with aortic stenosis. American Heart Journal. 1997; 133: 307-314.

[18] Qi W, Mathisen P, Kjekshus J, Simonsen S, Bjørnerheim R, Endresen $\mathrm{K}$, et al. Natriuretic peptides in patients with aortic stenosis. American Heart Journal. 2001; 142: 725-732.

[19] Di Nora C, Cervesato E, Cosei I, Ravasel A, Popescu BA, Zito $\mathrm{C}$, et al. New classification of geometric ventricular patterns in severe aortic stenosis: could it be clinically useful? Echocardiography. 2018; 35: 1077-1084.

[20] Bergler-Klein J, Klaar U, Heger M, Rosenhek R, Mundigler G, Gabriel H, et al. Natriuretic Peptides Predict Symptom-Free Survival and Postoperative Outcome in Severe Aortic Stenosis. Circulation. 2004; 109: 2302-2308.

[21] Henri C, Dulgheru R, Magne J, Caballero L, Laaraibi S, Davin L, et al. Impact of Serial B-Type Natriuretic Peptide Changes for Predicting Outcome in Asymptomatic Patients with Aortic Stenosis. Canadian Journal of Cardiology. 2016; 32: 183-189.

[22] Medranda GA, Salhab K, Schwartz R, Green SJ. Prognostic Implications of Baseline B-type Natriuretic Peptide in Patients Undergoing Transcatheter Aortic Valve Implantation. The American Journal of Cardiology. 2020; 130: 94-99.

[23] Nozohoor S, Nilsson J, Lührs C, Roijer A, Algotsson L, Sjögren J. B-Type Natriuretic Peptide as a Predictor of Postoperative Heart Failure after Aortic Valve Replacement. Journal of Cardiothoracic and Vascular Anesthesia. 2009; 23: 161-165.

[24] Sato K, Kumar A, Krishnaswamy A, Mick S, Desai MY, Griffin BP, et al. B-type natriuretic peptide is associated with remodeling and exercise capacity after transcatheter aortic valve replacement for aortic stenosis. Clinical Cardiology. 2019; 42: 270-276.

[25] Spargias K, Alexopoulos E, Thomopoulou S, Dimopoulos A, Manginas A, Pavlides G, et al. Effect of Balloon Valvuloplasty in Patients with Severe Aortic Stenosis on Levels of N-Terminal Pro-B-Type Natriuretic Peptide. The American Journal of Cardiology. 2009; 104: 846-849.

[26] Elbaz-Greener G, Ghanim D, Kusniec F, Rabin A, Sudarsky D, Carasso S, et al. Pre- and Post-Transcatheter Aortic Valve Replacement Serum Brain Natriuretic Peptide Levels and all-Cause Mortality. Cardiology. 2020; 145: 813-821.

[27] Redfield MM, Rodeheffer RJ, Jacobsen SJ, Mahoney DW, Bailey KR, Burnett JC. Plasma brain natriuretic peptide concentration: impact of age and gender. Journal of the American College of Cardiology. 2002; 40: 976-982.

[28] Wang TJ, Larson MG, Levy D, Leip EP, Benjamin EJ, Wilson $\mathrm{PWF}$, et al. Impact of age and sex on plasma natriuretic peptide levels in healthy adults. The American Journal of Cardiology. 2002; 90: 254-258.

[29] Clavel M, Malouf J, Michelena HI, Suri RM, Jaffe AS, Mahoney DW, et al. B-Type Natriuretic Peptide Clinical Activation in Aortic Stenosis. Journal of the American College of Cardiology. 2014; 63: 2016-2025.

[30] Ogawa N, Komura H, Kuwasako K, Kitamura K, Kato J. Plasma levels of natriuretic peptides and development of chronic kidney disease. BMC Nephrology. 2015; 16: 171. 